\title{
Mammalian Frontal Diploic Vein and the Human Foramen Caecum
}

\author{
J.G.M. THEWISSEN \\ Museum of Paleontology, University of Michigan, Ann Arbor, Michigan 48109
}

\begin{abstract}
The course of the frontal diploic vein in the mole Talpa and the tree shrew Tupaia is described and compared to the frontal diploic vein of other mammals. The frontal diploic vein in Talpa and Tupaia connects the dorsal sagittal sinus to the veins of the orbit and has an emissary function. In certain other mammals it has a diploic function and may drain towards the orbit (e.g., Orycteropus) or towards the dorsal sagittal sinus (e.g., Didelphis). The frontal diploic vein of these mammals is not homologous to the vein of the human foramen caecum, but to the human frontal diploic vein. The vein of the foramen caecum is a problematic structure: its incidence in embryos and children is not clear.
\end{abstract}

It is generally accepted that the mammalian venous system is more variable than the arterial or nervous systems. As a result little attention is paid to the venous system in comparative anatomical studies, and veins and associated structures are often misidentified or completely ignored. Comparative anatomical research shows that certain parts of the venous system are very constant within taxa, while interesting variations exist among taxa. In this paper the frontal diploic vein of mammals will be discussed as an example of such a structure. Its course and function in moles and tree shrews will be described, and inferences will be made about its function in these and other mammals. The proposed homology between the frontal diploic vein and the vein of the human foramen caecum will also be discussed.

The best published account of the frontal diploic vein in mammals is that of Miller's anatomy of the dog (Evans and Christensen, 1979). In the dog, the frontal diploic vein is small and appears in the orbit by means of a foramen in the postorbital process. It drains the frontal sinus and frontal diploë, and is usually connected to the dorsal sagittal sinus, but in some dogs this part of the vein is absent. The frontal diploic vein is small or absent in many mammals. It is sometimes a large structure, but is usually ignored in spite of its size even in those species. Clark (1926) noticed the presence of the "venous foramen" for the frontal diploic vein in the orbit of the tree shrew Ptilocercus, but gives no details, whereas later workers on tree shrews, such as Muller (1935) and Saban (1956-1957) do not discuss the structure at all.

\section{MATERIALS AND METHODS}

This study is based on observations on the anatomy of a European mole (Talpa europeae) and a tree shrew (Tupaia sp.). A series of transverse sections of a neonatal European mole was studied (Netherlands Institute for Developmental Biology, Utrecht; Hubrecht Collection, specimen number 194D). Each section is $0.009 \mathrm{~mm}$ thick, and stained with Ladewig's stain. An alcohol specimen of Tupaia (unnumbered specimen in the collections of the Museum of Paleontology, University of Michigan) was dissected using a dissection microscope at low magnification. Anatomical data on other mammals are from an extensive survey of cephalic characters previously reported on by Thewissen (1985).

\section{RESULTS}

The frontal diploic vein of the mole Talpa matches the size of the rostral part of the dorsal sagittal sinus, and forms an important connection between it and the veins of the ophthalmic plexus (Fig. 1). It originates from the rostral extremity of the dorsal sagittal sinus and enters a canal in the frontal bone through a bilateral foramen in the roof of the cranial cavity close to the sagittal plane, just caudal to the cribriform plate. Enclosed in the frontal bone, it extends laterally and ventrally. Its canal opens into the orbitotemporal fossa as a foramen rostral and dorsal to the optic and ethmoid foramina, but caudal to the eye. Although the vein has an emissary function in the mole, it seems reasonable to use the name frontal diploic vein because the vein is between two laminae of the frontal bone and is homologous to the frontal diploic vein of the dog.

The frontal diploic vein of the tree shrew Tupaia is comparable to, but not identical with, that of the mole. A common trunk for the bilateral vein branches off the dorsal sagittal sinus between the cerebrum and olfactory bulbs. The dorsal sagittal sinus does not terminate at the formation of this trunk, but extends rostrally. The trunk enters the frontal bone through a foramen to the right of the median plane. At its entry in the frontal bone, the trunk divides, forming the bilateral frontal diploic veins, which extend laterally between two laminae of the frontal bone and are comparable in size to the rostral portion of the dorsal sagittal sinus. The vein enters the orbit through a foramen in its roof just posterior to the supraorbital foramen and opens into the dorsal external ophthalmic vein which covers the frontal diploic foramen.

Received March 28, 1988; accepted July 20, 1988. 

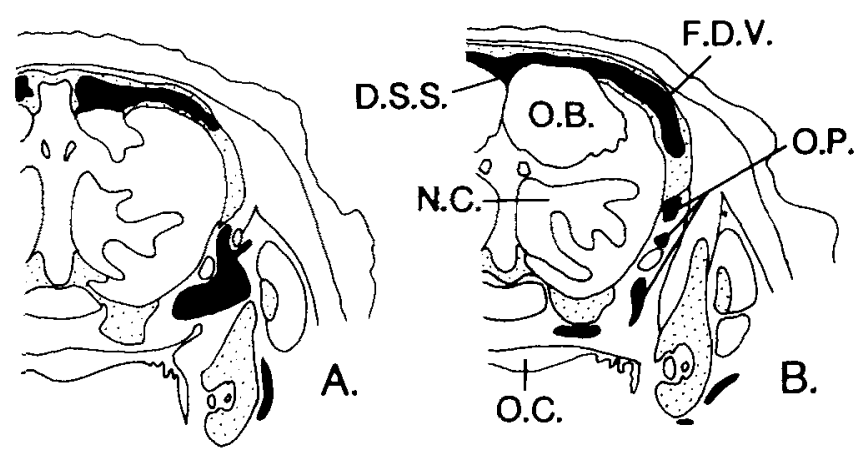

Fig. 1. Line drawings of transverse sections of neonatal European mole, Talpa europaea (specimen from Netherlands Institute for Developmental Biology: Hubrecht Collection 194D). Distance between rostral and caudal sections is approximately $1.1 \mathrm{~mm}$. D.S.S., dorsal sagittal sinus; E.V., ethmoid vein; F.D.V., frontal diploic vein; N.C., nasal cavity; O.B., olfactory bulb; O.C., oral cavity; O.P., ophthalmic plexus A: Section 41.8, rostral part of frontal diploic vein is between two laminae of frontal bone, dorsal sagittal sinus is caudal to this section.

\section{DISCUSSION}

The course of the frontal diploic vein in the surveyed mammals can be classified in one of three structurally different patterns. Moles (Talpa, Scalopus) and tree shrews (Tupaia, Ptilocercus) exemplify the first pattern: the frontal diploic vein connects the dorsal sagittal sinus to the veins of the orbit. Judging from the size of the vein, its importance in moles is greater than in tree shrews. A canal for the frontal diploic vein is also present in the subrecent tubulidentate Plesiorycteropus (Thewissen, 1985) and fossil insectivores such as Leptic tis. The orbital foramen for this vein in the latter was misidentified as the foramen for the lateral cerebral sinus by Butler (1956), and as the ethmoid foramen by Novacek (1986). The frontal diploic vein has the appearance of an emissary vein in moles, tree shrews, Leptictis, and Plesiorycteropus.

The second pattern of the frontal diploic vein is displayed by the dog and the aardvark (Orycteropus). In Orycteropus, the vein is larger than in the dog and drains the frontal sinus and frontal diplöe towards the orbit, it is not connected to the dorsal sagittal sinus (Thewissen, 1985). The endocranial part of the frontal diploic vein of Orycteropus and the dog (Evans and Christensen, 1979) is reduced, and the function of the remaining part is truly diploic.

The frontal diploic vein of a third group of mammals is diploic as in the second group, but here the orbital part of the vein is reduced. The frontal diploic foramen of the orbit in the opossum Didelphis is tiny, but one or more large foramina are present endocranially, connecting the dorsal sagittal sinus to the frontal sinus. In Didelphis, the frontal diploic vein presumably drains the mucous membrane of the frontal sinus and diploë of the frontal bone into the dorsal sagittal sinus. The direction of flow of venous blood is toward the cranial cavity, in contrast to Orycteropus, although the function of the frontal diploic vein in both species is diploic.

In summary, the frontal diploic vein functions as an emissary vein in some mammals, and as a diploic vein in others. The direction of bloodflow also differs between
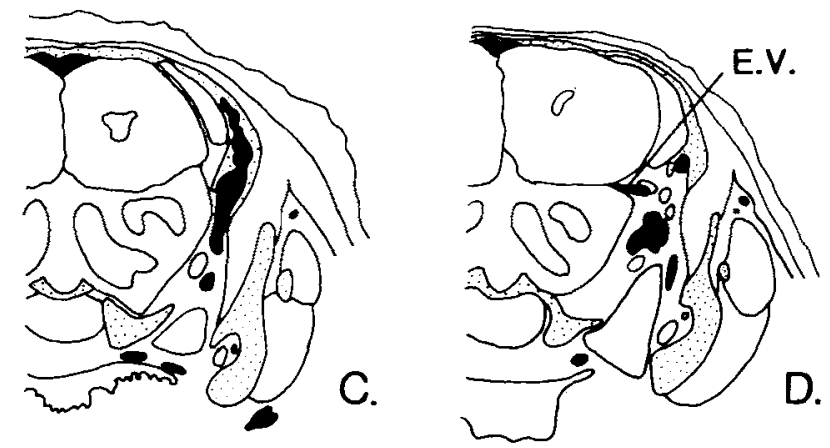

B: Section 44.10, frontal diploic vein connected to dorsal sagittal sinus, extending ventrally. Veins of the orbitotemporal fossa form a plexus around the optic nerve. C: Section 48.10, frontal diploic vein connected to ophthalmic plexus, but connection to dorsal sagittal sinus is lost. D: Section 53.2, frontal diploic vein is rostral to this section, ethmoid neurovascular group leaves the ventral part of the cranial cavity towards the orbit.

mammals: in moles, and possibly tree shrews, flow seems to be directed towards the cranial cavity, whereas in adult dogs and Orycteropus it is directed towards the orbit.

Padget (1957) refers to the most rostral tributary of the superior sagittal sinus in humans as the frontal emissary vein of the foramen caecum. In his plate 6, Padget homologizes this vein with the "anterior ethmoid vein" of the dog which, according to this plate, connects the dorsal sagittal sinus with the veins of the orbit by means of a foramen in the postorbital process, and is thus similar to what is called frontal diploic vein by Miller's anatomy of the dog.

Unlike the vein of the human foramen caecum, the frontal diploic vein of the dog is bilateral and not median, and enters the orbit instead of the nasal cavity. It originates at the narrowest point of the cranial cavity near the frontal lobe and it does not form the rostral termination of the dorsal sagittal sinus like the vein of the foramen caecum. The homology between the vein of the human foramen caecum and the frontal diploic vein of the dog, as suggested by Padget (1957), is therefore wrong.

Padget's (1957) term "anterior ethmoid vein" for the frontal diploic vein of the dog is incorrect. The ethmoid foramina connect the ventral side of the cranial cavity to the orbit, and carry a neurovascular group, whereas the orbital foramen for the frontal diploic vein connects the dorsal (superior) side of the cranial cavity to the orbit and carries only a vein. The ethmoid vein does not have important connections to the dorsal sagittal sinus like the frontal diploic vein, but enters the nasal cavity through the cribriform plate (Zuckerkandl, 1885). Ethmoid foramina are often located on the suture of the frontal bone, whereas the foramen for the frontal diploic vein pierces the frontal.

The true homologue of Padget's "anterior ethmoid vein" of the dog is the human frontal diploic vein. As in the dog, it opens near the supraorbital foramen and drains the diploë of the frontal bone into the supraorbital vein. 
Recognition of the homology of the frontal diploic vein of humans to that of other mammals leaves the problem of the homology of the vein of the foramen caecum. Zuckerkandl (1885) summarized the work of earlier anatomists on the foramen caecum, and concluded that it does not carry a functional vein in adults. More recently Kaplan et al. (1973) found no traces of large veins in the foramen caecum of 201 humans, although microscopic arteries and veins were noticed. Boyd (1930) found that three human skulls in a sample of 212 had a foramen caecum that did not end blind: in two the canal of the foramen caecum ended by a foramen in the nasal bone on the face, and in one the canal traversed the frontal sinus and opened into the nasal cavity. In all three cases the lumen of the canal was so narrow that only a hair could be passed through it.

Padget (1957) found no traces of the vein of the foramen caecum in embryos up to 3 months, although other emissary veins of the cranial cavity develop before 2.5 months. Zuckerkandl (1885) stated that the foramen caecum connects the superior sagittal sinus with the veins of the face and is related to the nasal bone in the newborn, but did not notice connections to the veins of the nasal cavity. This contradicts Gray's anatomy (Williams and Warwick, 1980), which stated: "The superior sagittal sinus ... receives a vein from the nasal cavity on the rare occasions when the foramen caecum is patent"' (p. 744).

Most sources agree on the absence of functional veins in the foramen caecum in adults, and it seems likely that it is also absent in human embryos before the fourth month. Kaplan et al. (1973) and Browder and Kaplan (1976) found no traces of veins in the foramen caecum of children and late embryos, but although the same sample was used in both studies, the data on the ages of their specimens are inconsistent in the two publications (see also Kaplan et al., 1972). It seems likely that their sample included some specimens of 6 to 7 months of gestation, and possibly some $\leqslant 1$-year-old children.

Although absent in human adults and embryos, a vein through the foramen caecum may be present at some stage in early life of certain individuals. A single welldocumented case was published over 100 years ago (Zuckerkandl, 1885). No data on frequency and age distribution of the vein are available.

\section{ACKNOWLEDGMENTS}

I thank Dr. G. Bangma and the Hubrecht Laboratorium, Netherlands Institute for Developmental Biology, Utrecht, for access to the described mole specimen and Dr. P.D. Gingerich (University of Michigan) for permission to dissect the tree shrew. I thank Dr. R. Presley (University College, Cardiff) for pointing out the ontogenetic aspects of the frontal diploic vein, Drs. T. Gest and T. Fischer (University of Michigan) and Mr. C. Spoor (University of Groningen) for advice concerning the foramen caecum, and Ms. E. Culotta, Dr. T. Gest, and Mr. A.v. Nievelt for commenting on the manuscript. I also thank Mr. H. Kaplan for correspondence on the dataset that he described.

\section{LITERATURE CITED}

Boyd, G.I. 1930 The emissary foramina of the cranium in man and the anthropoids. J. Anat., 65:108-121.

Browder, J., H.A. Kaplan 1976 Cerebral Dural Sinuses and Their Tributaries. Thomas, Springfield IL

Butler, P.M. 1956 The skull of Ictops and the classification of the Insectivora. Proc. Zool. Soc., Lond., 126:453-481.

Clark, W.E. Le Gros (1926) On the anatomy of the Pen-Tailed TreeShrew (Ptilocercus lowii). Proc. Zool. Soc., Lond. :1179-1309.

Evans, H.E., G.C. Christensen 1979 Miller's Anatomy of the Dog. Saunders, Philadelphia.

Kaplan, H.A., A. Browder, J. Browder 1973 Nasal venous drainage and the foramen caecum. Laryngoscope, 83:327-329.

Kaplan, H.A., J. Browder, J.J. Knightly, B.F. Rush, A. Browder 1972 Variations of the cerebral dural sinuses at the torcular herophili. Am. J. Surg., 124:456-461.

Muller, J. 1935, for 1934 The orbitotemporal region of the skull of the Mammalia. Arch. néerlandais Zool., 1:118-260.

Novacek, M.J. 1986 The skull of leptictid insectivorans and the higherlevel classification of eutherian mammals. Bull. Am. Mus. Nat. Hist., 183:1-112.

Padget, D.H. 1957 The development of the cranial venous system in man, from the viewpoint of comparative anatomy. Contrib. Em. bryol., 36:81-151.

Saban, R. 1956-1957 Les affinitées du genre Tupaia Raffles, 1821, d'après les caractères morphologiques de lat tête osseuse. Ann. Paleontol. 42:170-224; 43:1-44.

Thewissen, J.G.M. 1985 Cephalic evidence for the affinities of tubulidentata. Mammalia, 49:257-284.

Williams, P.L., R. Warwick 1980 Gray's Anatomy. Saunders, Philadelphia, 36th ed.

Zuckerkandl, E. 1885 Über den Circulations-apparat in der Nasenschleimhaut. Akad. Wissench. Wien, Math. Naturwissensch. Kl., Denkschr., 49:121-152. 